\title{
Unha ollada á narrativa dos noventa
}

\author{
Miguel Louzao
}

\section{PARTIDA}

A sempre dificultosa experiencia da periodización literaria pode levarnos a conxecturar tantas etapas coma lectores e, moitas veces, batallas irresolúbeis que só o paso do tempo, entre outros factores canonizadores, determinará. Nós, nestas páxinas, non pretendemos entrar en criterios de periodización, tanto pola inmediatez da materia tratada como porque simplemente cremos que non existen balizas posíbeis que determinen a existencia de rupturas, nin xeracionais nin ficcionais, nos anos noventa. Así pois, tomamos esta década como materia de estudio sen outra intencionalidade que ofrecer unha breve e persoal ollada á producción narrativa destes anos, deixando para outra ocasión o relativo á literatura infantil e xuvenil que tan gozoso existir está a ter entre nós.

\section{BREVE ENCADRAMENTO POLÍTICO-CULTURAL}

Nestes anos (1990-2000) a situación socio-política galega estivo marcada de xeito fulcral pola presencia dun goberno autonómico de poder case absoluto, que está aínda a acentuar o proceso de folclorización da lingua galega, coas consecuencias que Antón Figueroa sinalou a respecto de tal fenómeno1, e a

1 Antón Figueroa, Diglosia e texto, Vigo, Xerais, 1988, di entre outras cousas: «Cóntase co texto B, si, pero para reducilo máis ou menos conscientemente, para lelo sen ningún compromiso coa historia e polo tanto sen ningunha posibilidade real de «significancia» para o propio lector, como non sexa a de documentarse ou a de aumenta-la erudición». Máis adiante engade «Este tipo de lectura accidental (...) é constatable explicitamente en certos casos, por exemplo, cando na escola se propoñen lecturas en galego «ás veces», en certas utilizacións de textos nos 
incidir, de xeito máis ou menos explícito, no silenciamento, cando non ocultamento, de certos escritores e obras en lingua galega. Neste momento, coma noutros sectores, o papel que a administración galega desenvolve na promoción e difusión da literatura galega oscila -segundo un sector da crítica- «entre o intervencionismo e a pasividade» 2 . Así pois, ese laissez faire provoca unha estabilización, cando non un recuamento, da aplicación da Lei de Normalización Linguística e ao tempo unha perda progresiva e perigosa de falantes entre as xeracións máis novas, casualmente as máis alfabetizadas na lingua de Galicia e as maiores consumidoras de literatura nas escolas e institutos. Mais, estas xeracións vense desvalidas socialmente, agás naqueles casos de militancia ou traballo profesional, unha vez que superan estes anos escolares, polos preconceptos xa clásicos a respecto da lingua e da literatura galega (diglosia, modernidade, ruralismo, etc) e pola deixadez de funcións á hora de invertelos por parte de quen ten poder para facelo.

Outro tanto se podería dicir da situación a nivel dos medios de comunicación, que, combinando a mestura explosiva dunha rémora xa antiga a respecto da situación linguística e cultural galega e unha dependencia/submisión (económica, política, cultural, etc.) enorme do poder autonómico, chegan a ningunear, ignorar e contribuír tamén á folclorización da literatura galega, mantendo sempre o status de cultura A para a española. Relacionado con isto está a promoción dos escritores nacidos en Galicia que escriben en castelán, e que sempre saen con ampla reportaxe gráfica e con declaracións sobre a súa orixe galega, sobre o amor pola súa cidade (vila, aldea, etc.) e con louvanzas á beleza de Galicia ${ }^{3}$. Tamén é frecuente que se destaquen aqueles escritores galegos que escriben/escribiron en galego e en español ${ }^{4}$, continuando a aplicar esa científica teoría do bilingüismo harmónico que o poder político autonómico defende, e chegando mesmo ao paroxismo sucursalista de dar maior cobertura ás obras de autores galegos traducidas ao español con motivo da súa presentación en Madrid que cando se trata da presentación da obra orixinal en galego.

\section{SITUACIÓN EDITORIAL}

No mundo editorial, no que se refire á narrativa, seguiron a ser fundamentalmente tres as casas editoriais de resultados eficaces: Sotelo Blanco, en

medios audiovisuais, en celebracións ocasionais máis ou menos académicas; é constatable esta actitude, dicimos, en exemplos puntuais, pero, o peor é que pode constituír unha, ou a única, actitude de lectura de grande parte dos lectores mentres a lingua B sexa lingua B», p. 83 e ss.

2 Dolores Vilavedra, Historia da literatura galega, Vigo, Galaxia, 1999, p. 272.

3 Como se pode ver en Rodri Garcla e C. FERNÁNDEZ, «Lola Beccaría: «Soy optimista, la vida diaria tiene muchas aventuras», La Voz de Galicia, "Cultura», 9 xaneiro 2001, p. 26.

4 Vid. un exemplo en Rodri García e C. Fernández., «Cunqueiro, primer gallego que ganó el Nadal», La Voz de Galicia, «Cultura», 9 xaneiro 200, p. 26. 
menor medida; Galaxia, coa estabilidade que lle daba contar no seu catálogo con autores fixos; e sobre todo Edicións Xerais de Galicia, que, alén de contar con autores case en exclusiva (Méndez Ferrín, entre eles), tiña un premio literario asentado que lle permitía publicar a obra gañadora e ter moi á man as obras finalistas, mantiña unha actitude que se ten considerado máis agresiva ${ }^{5}$, pero que lle facilitaba chegar aos lectores. Por este motivo, moitos autores acabaron incorporándose a esta editorial. En 1990 naceron Do Cumio, Laiovento, Nigra, Novo Século, Bahía e Positivas. Esta última editorial incidirá na procura de formas narrativas máis innovadoras. En 1991 apareceu Espiral Maior que, ademais do seu encomiábel labor poético, fixo esforzos importantes por comezar unha colección narrativa que xa deu os seus froitos. Por último, comezaron os selos Edebé-Rodeira en 1992, Tambre en 1993 e Tris-Tram en 1995.

A convivencia de todos estes selos non supuxo un incremento destacábel da producción narrativa, como pode observarse nas «Estatísticas» dos Informes de Literatura Galega ${ }^{6}$ dos últimos cinco anos da década.

\section{A CRÍTICA}

Canto á crítica, podemos dicir que se produciu unha especialización, pois á beira das revistas xa clásicas, coma Grial, e outras de certa bagaxe, coma Luzes de Galiza e Festa da Palabra Silenciada, naceron en 1989 o Boletín Galego de Literatura, en 1990 A Trabe de Ouro e Seiva (xa desaparecida), en 1991 Animal+l e en 1993 o Anuario de Estudios Literarios Galegos. En 1997 xurdiu a «Revista de Información para o debate» Tempos Novos, que dedicaba certo espacio, e varios especiais, á literatura; en 1998 apareceu Eidos do Libro, frustrado intento de crear unha revista de crítica, estudios e novidades literarias de calidade que duraría só uns meses; e a finais de 1998 naceu a Guía dos Libros Novos, revista mensual en formato de xornal integramente dedicada ás recensións das obras literarias acabadas de saír. A isto hai que lle sumar os suplementos literarios dos xornais ${ }^{7}$ e en formato internet a revista Ómnibus $^{8}$.

5 Vid. Dolores VILAVEDRA, «Narrativa do 93: tempos de crise, tempos de escolma», Anuario de estudios literarios galegos 1993, Vigo, Galaxia, 1994, pp. 207-212.

6 Vid. «Estatísticas» en Blanca-Ana RolG Rechou (coord.), Informe de Literatura 1995, 1996. 1997, 1998 e 1999, Santiago de Compostela, Centro Ramón Piñeiro de Investigación en Humanidades, 1996, 1997, 1998, 1999 e 2000 . Aquí, ademais, pode comprobarse que o número de títulos de narrativa publicados nestes cinco anos oscilou entre os 38 de 1998, como cifra máis baixa, e os 57 de 1999, como cifra máis elevada.

7 Culturas en La Voz de Galicia, Revista das Letras, Artes e Ciencias en O Correo Galego, o Correo das Culturas en El Correo Gallego, El Sábado no Faro de Vigo, entre outros.

8 Seguramente deixemos no tinteiro moitas outra publicacións non específicas de literatura nas que tamén se lle dá cabida á crítica, polo que para máis información ao respecto o lector interesado pode consultar en Blanca-Ana RoIG RECHOU (coord.), Informe de Literatura 1995, 1996, 1997,1998 : 1999, cit. 
Todos estes soportes axudan a configurar un corpus crítico que, malia as súas grandes eivas, nunca foi tan amplo e plural no sistema literario galego. Estes novos espacios non impiden que as «capelas» sigan a funcionar e a controlar moitos estados de opinión que se fan difíciles de traspasar.

\section{OS PREMIOS}

Nesta década, alén dos certames xa clásicos e basilares, como xa ten considerado Xoán González-Millán 9 (Premio Xerais de Novela e Premio Blanco Amor), naceron os premios García Barros (1989), Cidade de Lugo (1990), xa desaparecido, Álvaro Cunqueiro (1991), e o Vicente Risco de Literatura Fantástica (2000). Outro dos certames aparecidos é o Premio Torrente Ballester (1989) ao que concorren obras en galego e en castelán. A grande relevancia que acada este certame nos medios de comunicación contrasta co tratamento informativo que recibe o Premio Eixo Atlántico (1998), ao que poden presentarse orixinais escritos en galego e en portugués. Neste contex to de multitude de premios 10 continuamos, en certa medida, aínda hoxe, nun estado no que conquerir un premio supón unha vía para a publicación, mais xa non é garantía de continuidade do éxito editorial, nin do regreso aos andeis con futuras obras, nin de canonización 11 .

Polo demais, xorde un elemento novo a ter en conta: algúns autores tiveron, quer por un apoio editorial decidido, quer por un apoio mediático explícito, unhas condicións máis benévolas á hora de publicar e chegar aos lectores, alén da súa calidade literaria. Referido a isto último podemos achar matices comparativos, en función dos medios de comunicación, das afinidades ideolóxicas, etc., xa que, tendo en conta a facilidade para chegar aos lectores, foron acollidos de xeito desigual. Repárese, por exemplo, nos casos contrapostos de Manuel Rivas e Alfredo Conde. Por outra parte, isto vén ser unha pauta máis da normalidade, malia haber tamén caxatos económicos e ideolóxicos de por medio. Con todo, téñase en conta, a modo de exemplificación de calidade creativa e acollida dos lectores, o caso de Xurxo Borrazás, que nunca se presentou a un premio literario ${ }^{12}$. Velaquí un inequívoco síntoma de normalidade, como noutrora se prevía ${ }^{13}$.

9 Vid. X. GonZÁlez-Millán, A narrativa galega actual (1975-1984), Vigo, Xerais, 1996, pp. 58-67.

10 Aquí só traemos a colación os máis relevantes, mais para comprobar unha relación exhaustiva dos moitos premios que existen hoxe na literatura galega Vid. Blanca-Ana RoIG ReCHOU (coord.), Informe de Literatura 1995, 1996, 1997, 1998 e 1999, cit.

11 Así, moitos dos textos premiados non deixan de ter un «éxito" puntual e pasaxeiro.

12 Un mostra da boa recepción foi a súa novela Criminal (Santiago de Compostela: Sotelo Blanco, 1994) que recibiu o Premio Arcebispo Juan de San Clemente no que participan todas as obras de narrativa en galego publicadas e que non conceden os críticos senón os propios lectores.

13 En Silvia GASPAR, «A narrativa excéntrica (1985-1995)», Vigo, Grial, 127, xullo-agostosetembro, 1995, dise «Pero ese proteccionismo subvencionador encabezado por institucións 


\section{SITUACIÓN DA NARRATIVA}

Se botamos unha ollada ás panorámicas sobre o xénero feitas ao longo da década e ás referencias da prensa (maiormente $A$ Nosa Terra e $O$ Correo Galego) constatamos a situación irregular que atravesou a narrativa galega nestes anos, que moitas veces se reflicte en expresións como «minguada colleita narrativa do $93 » 14$ ou «O ano narrativo 1994 cerrouse cun balance altamente positivo no que se refire á producción» 15 . Ambas citas veñen evidenciar a inestabilidade da narrativa galega en canto á cantidade, á que anteriormente fixemos referencia.

No que se refire ás experiencias narrativas, ata mediados da década houbo composicións que buscaban ampliar horizontes ao tempo que cubrir espacios aínda baleiros na literatura galega. Así, escribíanse e promovíanse obras baseadas no erotismo, no mundo da modernidade e na novela negra, que tivera exitoso precedente en Crime en Compostela (Vigo, Xerais, Premio Xerais, 1984) de Carlos G. Reigosa, e coñeceu un dos principais seguidores, con varias obras recoñecidas, en Aníbal Malvar. Para apoiar estas novas propostas naceron coleccións («Negra» en Xerais, etc) e premios (Premio Semana Negra de novela curta); promovéronse volumes colectivos (nomeadamente en Edicións Xerais) e certames de narrativa erótica (Premio de Narración Erótica de Edicións Positivas). Por outra parte, a ciencia-ficción tivo un lento arranque aínda que conseguiu obras galardoadas en premios non específicos.

A partir da metade da década produciuse a transgresión das premisas requiridas por un sistema literario en «permanente fundación», o que permite falar dunha pluralidade de voces, formas e intencións con respecto aos anos anteriores, seguramente por atoparse moitos deses baleiros xa cultivados. Así temos, entre outras liñas narrativas, obras ( ¿ou autores?) de marcada intencionalidade culta, exemplo explícito son as de Carlos Caneiro, mais tamén a de Victor F. Freixanes, entre outros. Noutra liña sitúanse textos de menor complexidade e de feitura máis comercial, o que non implica un desmerecemento artístico (nomeadamente as de Fran Alonso). Outros autores andaron na procura de novos camiños creativos e novas formas (coma Xavier Queipo, ou Xurxo Borrazás, como veremos).

Esta división das tendencias temáticas da década carece de validez para se referir a algúns autores que non se involucraron na procura de novas vías,

públicas e mercantís, xa minuciosamente cuestionado, non pode dilatar moito máis esa situación inflacionaria que, segundo a súa propia dinámica de creación, recepción e venda, tenderá a normalizarse a medio prazo", p. 320.

14 Dolores VilaVedRA, «Narrativa do 93: tempos de crise, tempos de escolma», cit., p. 207.

15 Silvia GASPAR, «Narrativa: o caos que precede a orde», Anuario de Estudios Literariós Galegos 1994, Vigo, Galaxia, 1995, p. 163. 
senón que mantiveron case inmutábel unha liña xa marcada desde o comezo da súa producción.

Neste anos conviviron no sistema literario galego obras fragmentarias, linguaxes opostas, unhas máis líricas, outras máis narrativas, aquelas máis históricas e lendarias, estas máis realistas ou de temática contemporánea, novela negra, erótica, e combináronse liñas de temática tradicional de dimensión máxica cunha liña de temática urbana. Por todo isto, a narrativa galega foi indo, paseniñamente, cara á normalidade, ou, como se ten sinalado noutros termos, cara a unha situación na que «o escritor galego aspira a construír mundos novelescos que lle concedan primeiro o nacionalismo e logo a universalidade» 16 , entendendo isto como xeito de se inserir na literatura nacional, posto que o nacionalismo literario, que predominou ata mediados da década dos oitenta ${ }^{17}$, xa só presenta algunhas serodias manifestacións.

En canto aos lectores, estes son poucos e filoloxizados, cos perigos que neste sentido anunciou Antón Figueroa ${ }^{18}$, agás no caso da obra de Manuel Rivas ${ }^{19}$. Pero sobre todo débese ter en conta que, como dixo Suso de Toro, «hoxe, todos, empezando polos editores, sabemos que os lectores son, sobre todo, lectoras» 20 . Pois ben, se miramos o número de narradoras que aparece en calquera relación de escritores (catálogos, editoriais, estudios, etc), os datos non deixan de resultar elocuentes ao respecto: é ínfimo, máxime se o comparamos coa eclosión que a poesía escrita por mulleres tivo no noso país nesta década. Con intención de cubrir, incentivar e promover estoutra eiva na nosa narrativa, veu luz no ano 2000 unha colección de relatos que, segundo se indica, «quere inaugurar un espacio case inédito nas nosas letras: a narrativa de muller»21. Fican, pois, os camiños abertos para que nos próximos anos a necesaria emancipación feminina se produza tamén na narrativa.

16 María Luís GAMALLO, «A narrativa galega dos noventa: cara a consolidación dunha nova novela", Boletín Galego de Literatura, n. ${ }^{2} 24,2 .{ }^{9}$ Semestre, 2000. (No prelo)

17 Cfr. X. GonZÁlez-MiLláN, X., A narrativa galega actual (1975-1984), cit., o apartado titulado "A lexitimación dun sistema literario nacional", onde se di que «A partir de 1975, e sobre todo na década seguinte, obsérvase unha alteración desta fórmula: o texto literario gaña independencia con respecto ás imposicións do nacionalismo literario, e os axentes e institucións que protagonizan esta nova lectura reciamian a lexitimación da súa propia autonomía», p. 29.

18 Cfr. Antón Flgueroa, Diglosia e texto, cit. alí dise entre outras cousas: "...nunha situación diglósica, onde existen algúns dos factores que levamos apuntados, e algúns outros máis, levan a algo que nós chamariamos «filoloxización» da lectura, que en definitiva constitúe un fenómeno lóxico e lexítimo de militancia, pero que ímplica gravísimos riscos para o funcionamento -produccción e recepción- normal de textos literarios», pp. 51-54.

19 Non é aquí o lugar de falarmos da necesaria distinción entre público comsumidor e público lector, pero sería moi interesante considerar esta cuestión.

20 Suso DE TORO, «Dificultades para as literaturas nacionais», Boletín Galego de Literatura, n. ${ }^{9} 17,1 .^{9}$ semestre, 1997, pp. 119-130.

21 Teresa Cuiñas e Iria Sobrino Freire, «Prologo» a Narradoras, Vigo, Xerais, Col. Abismos, 2000, pp. 6-7. 


\section{ALGÚNS AUTORES E OBRAS DA DÉCADA}

Nas páxinas seguintes intentaremos ofrecer unha selectiva panorámica comentada da prosa galega da década dos noventa. Ao dicirmos galega queremos dicir en lingua galega, pois unha das normas sistémicas que o sistema literario galego dilucidou ao longo destes últimos vintecinco anos é o criterio lingüístico, algo que xa deixara claro, entre outros, o profesor Ricardo Carballo Calero 22. Así pois, escollemos autores e obras que, segundo o noso criterio, acadaron certa relevancia no conxunto da narrativa galega destes anos, e só estas, non todo o corpus novelístico dos escritores. Isto non quere dicir que non falten escritores xa consolidados que nos deixaron boas obras no pasado ou autores novos que a penas se deron a coñecer e que poidan chegar a darnos boas sorpresas no futuro. Tampouco se debe entender que esta ausencia na nosa clasificación estea motivada pola falta de valía creativa. Simplemente, consideramos aquelas obras que por un motivo ou por outro sobresaíron no sistema literario galego.

No evoluír da narrativa desta década conviven escritores de varias xeracións: desde os máis veteranos aos que comezaran a súa andaina na década anterior e, por último, os máis novos que, en varios casos, publicaron a primeira obra nestes anos ata o punto de que algún deles deu a luz varios volumes que o converten xa nun referente obrigado ao falarmos do xénero narrativo galego contemporáneo.

\subsection{ESCRITORES XA CONSAGRADOS NO COMEZO DA DÉCADA}

En XAVIER Alcalá (Miguelturra, Ciudad Real, 1947) temos a un escritor amplamente recoñecido nas nosas letras que contribuíu con éxito á popularización da literatura galega nos primeiros anos de implantación da lingua galega no ensino e que serviu de referencia obrigada para moitos rapaces daquela altura coa obra $A$ nosa cinza (Vigo, Galaxia, 1987). Nesta década publicou varios libros que seguen a demostrar a frescura estilística coa que se adentrou na chamada literatura de viaxes, localizados na Arxentina, con obras como Latitude Austral (Vigo, Xerais, 1991), Arxentina (Vigo, Xerais, 1990), etc., ou en Cuba, con La Habana Flash (Vigo, Galaxia, 1998), coas que pretendeu facer unha crónica da Galicia exterior. Destas viaxes naceron varios volumes de contos (Contos das américas, Vigo, Xerais, 1992; Contos do Impaís, Vigo, Xerais, 1992; etc.) e a novela gañadora do Premio Blanco Amor en 1998, Alén da desventura (Vigo, Galaxia, 1998; Premio Blanco Amor 1998), na que se acumulan

22 Ricardo Carballo Calero, Historia da literatura galega contemporánea, Vigo, Galaxia, 1981 (3.' ed.), p.11. 
historias, personaxes, ambientes e atmosferas no marco histórico do último tercio do século XVII.

Carlos Casares (Xinzo de Limia, 1941) deu a luz nestes anos unha única novela, Deus sentado nun sillón azul (Vigo, Galaxia, 1996), que volve pór de manifesto a consideración deste autor coma un grande narrador dos nosos tempos. Nesta obra hai diferentes xogos narrativos, tantos coma lecturas, nos que se trocan constantemente os narradores, o que non empece que o o ritmo lento de moitas páxinas relantice en exceso a acción e con ela a atención do lector ${ }^{23}$.

O escritor ALFREDO CONDE (Allariz, 1945) achegounos tres publicacións durante este período. Trátase de Sempre me matan (Vigo: Ir Indo, 1995), que supón o comezo dunha triloxía sobre a emigración galega contemporánea protagonizada por Blas Carou, un emigrante que ve frustradas as súas ambicións polas envexas e incomprensións. A segunda entrega foi $O$ fácil que é matar (Vigo, Xerais, 1998), na que continúa a recrear os enredos dos políticos, dos empresarios, etc, e onde aparecen identificábeis certos persoeiros da vida pública galega. Finalmente publica A casa de Adara (Vigo, Xerais, 1996), conxunto de irónicos relatos de grande intensidade no que insiste nos temas xa habituais neste autor.

Xosé Fernández Ferreiro (Nogueira de Ramuín, 1931), publicou neste anos a novela $O$ atentado (Vigo, Xerais, 1994), na que continúa a temática mítico-popular, característica de grande parte da súa obra anterior, neste caso mediante a recreación da emigración madrileña dun mozo do Val de Lemos que devece por voltar á súa mitificada aldea. Este pouso tamén se rastrexa en $C o$ medo nas mans (Vigo, Xerais, 1996), obra fantástica de xinea popular. Mais foi con Agosto do 36 (Vigo, Xerais 1991), cando acadou os maiores recoñecementos. Non só por tratar dun tema (a guerra civil) moi socorrido, senón pola minuciosidade e precisión narrativa, cunha grande dose de intriga, suspense e terror «combinado coas fortes paixóns desatadas pola carraxe e polo amor» 24 .

A única entrega narrativa de VICTOR F. FreiXaNEs (Pontevedra, 1951) nesta década foi $A$ cidade dos Césares (Vigo, Xerais, 1993), que supón a continuidade no seu proxecto de recreación histórica coas características propias dunha epopea, que, a pesar das moitas enumeracións e dos períodos longos que diminúen o fluír narrativo, posúe grande riqueza léxica e un ton apocalíptico decorado con varios símbolos que a converten nunha obra de grande ambición.

A propósito de Xosé Luf́s Méndez Ferrín (Ourense, 1938) precisariamos moitas páxinas para falarmos de todo o que deu de si nesta década. Pechouna coa novela No ventre do silencio (Vigo, Xerais, 1999; Premio Eixo

23 Quixeramos só citar aquí o ensaio titulado Un país de palabras (Vigo, Galaxia, 1998), no que, cun estilo máis áxil e ameno, calidade que caracteriza o seu xeito de escribir desde sempre, podemos observar as súas reflexións culturais que demostran o seu alto valor intelectual.

24 Xosé Manuel Salgado, «O compromiso de Xosé Fernández Ferreiro. Agosto do 36», A Trabe de Ouro, Tomo IV, Ano III, outubro-novembro-decembro, 1992, p. 582. 
Atlántico 1999), na que presenta un mundo narrativo-ficcional poderosísimo, que desborda o lector pola densidade narrativa, pola concentración estilística, pola claridade e plenitude na recreación da Compostela que o escritor coñeceu na súa xuventude. Esta obra, segundo afirmou o propio autor, vén rematar a triloxía comezada con Antón e os Inocentes (Monforte de Lemos, Xistral, 1976) e continuada con Bretaña, Esmeraldina (Vigo, Xerais, 1997). Mais, Méndez Ferrín comezara a década presentando un extraordinario libro de relatos, Arraianos (Vigo, Xerais, 1991), que acadou cumios narrativos-ficcionais moi elevados, logrados cunha grande riqueza lingüística. Estes relatos achégannos un mundo en conflicto, con retallos de vida angustiosa, cunha marcada violencia e represión, quer co trasfondo político explícito, quer cun fondo imaxinario misterioso, cunha ficción determinada pola realidade, $o$ que Xesús González Gómez denominou «imaxinación comprensiva» 25. Recentemente a AELG denominouno candidato da literatura galega ao Premio Nobel.

Foi en 1999 cando Xosé Neira Vilas (Vila de Cruces, 1928) volveu publicar unha obra narrativa para adultos, logo de se dedicar con máis intensidade á literatura infantil e ás pescudas histórico-literarias sobre a diáspora galega. Trátase de $O$ home de pau (Vigo, Xerais, 1999), conxunto de relatos de ton inocente, infantil diriamos, escritos cun estilo esencialista, cunha prosa contida e coa economía linguiística que caracteriza a súa obra. $O$ recurso alegórico sérvelle para defender unha actitude vital de rexeitamento do maquinismo e da insolidariedade das cidades do noso tempo e propor como alternativa a volta aos valores tradicionais e de defensa do medio natural.

Xosé Manuel Martínez OCa (A Estrada, 1942) publicou, entre outras, a novela Diario de inverno (A Coruña, Bahía, 1994) na que, partindo da técnica do manuscrito encontrado, o lector vai descubrindo a vida dun esquizofrénico namorado dunha muller imposíbel. Toda a diéxese conta cunha estructura preconcibida, a dun diario, capaz de enredar ao lector e atrapalo na ficción. A segunda entrega foi Náufragos en terra (Os amores imposibles) (Vigo, Xerais, 1995). Trátase de seis relatos que teñen en común un protagonista masculino e o tema do amor imposíbel narrado con varios rexistros, algo xa coñecido no autor, cos que recrea espacios sentimentais

A escritora MARf́a Xosé QUEIZÁn (Vigo, 1939), despois da viraxe narrativa e temática que supuxo Amantia (Vigo, Xerais, 1984), publicou obras protagonizadas por mulleres como Amor de Tango (Vigo, Xerais, 1992) ou Ten o seu punto a fresca rosa (Vigo, Xerais, 2000), nas que recrea unha literatura urbana con momentos poéticos de grande intensidade. Outra súa obra foi $O$ solpor $d a$ cupletista (Vigo, Nigra, 1998), relato ben construído de ton claramente evocador no que se recupera a figura da «Bella Otero».

25 Xesús GonzAlez Gómez, «A última narrativa de X.L. Méndez Ferrín: da utopía á historia», Grial, 127, xullo-agosto-setembro, Tomo XXXIII, 1995, p. 413. 


\subsection{ESCRITORES QUE COMEZARON A PUBLICAR NOS ANOS OITENTA E QUE ALCANZARON CERTO GRAO DE PLENITUDE CREATIVA NOS NOVENTA}

Na primeira novela de MARILAR AleIXANDRE (Madrid, 1947) Tránsito dos gramáticos (Vigo, Xerais, 1993), destaca o tratamento dos personaxes marxinais e a alta dose de intriga, así como o ritmo dunha narrativa na que se combinan moitos ingredientes con grande viveza estilística. Estas características están tamén presentes en A compañía clandestina de contrapublicidade (Vigo, Galaxia, 1998; IV Premio Álvaro Cunqueiro) onde se engaden elementos da novela fantástica e sentimental cunha perspectiva crítica da sociedade. Na mesma órbita sitúase Lobos nas illas (Vigo, Xerais, 1996), obra a cabalo entre a realidade e a ficción con diversos estilos e puntos de vista narrativos, arrastra ao lector cunha prosa directa.

Darfo Xohán Cabana (Roás, 1952), despois de se estrear como narrador con grande éxito, de crítica e lectores, resultou gañador do Premio Xerais de Novela 1989 a finais da década anterior con Galván en Saor (Vigo, Xerais, 1989). Nestes anos publicou, entre outros, Fortunato de Trasmundi (Vigo, Xerais 1990), unha fábula moral de pouca fortuna; Vidas senlleiras (Vigo, Xerais 1992), conxunto de relatos breves de xinea fantástica; $O$ cervo na torre (Vigo, Xerais, Premio Xerais de Novela 1994), na que se procura a reconstrucción da intrahistoria de Galicia ao tempo que converte este espacio nun estado socialista; e Morte de Rei (Vigo, Xerais 1996), obra que, amosando unha poderosa erudición e un minucioso labor de documentación, reconstrúe a pasaxe histórica da traizón ao rei galego Don García. Cuns modelados personaxes, nomeadamente o rei, e con axilidade narrativa consegue desenvolver unha trama argumental na que transloce a importancia dun momento histórico clave para Galicia.

Logo do salto á narrativa nos anos finais da década pasada, RAMIRO FONTE (Pontedeume, 1957) deu ao prelo obras como Os leopardos da lúa (Vigo, Galaxia, 1993), novela de iniciación sentimental situada na Compostela estudiantil con doses de intriga policíaca expresada cun marcado lirismo.

Carlos G. Reigosa (Lagoa de Pastoriza, 1948) publicou $A$ guerra do tabaco (Vigo, Xerais, 1996). Esta obra cumpre estrictamente as características da novela negra e está protagonizada polo xa coñecido detective Nivardo Castro, que tamén fora o personaxe principal na exitosa novela Crime en Compostela (Vigo, Xerais, 1984; Premio Xerais de novela 1984) que acadara grande repercusión por ser o referente primeiro da novela negra en galego.

Despois dunha longa ausencia nas librerías, volveu ANXo REI BALLESTEROS (Codeso, Boqueixón, 1952) cunha novela de moita intensidade, Loaira (Galaxia, 1992), na que se combinan múltiples discursos e modos narrativos dun xeito moi complexo. Anos máis tarde, ofreceunos A sombra dos teus soños (Vigo, Galaxia, 1998), onde tece seis relatos nunha linguaxe máis directa e coloquial, nos que fala do sexo, do amor, da violencia e da morte. 
O polígrafo AnTón Risco (Allariz 1926-Vigo 1998) deu a luz varias obras, entre as que sinalamos as seguintes: Mascarada (Vigo, Galaxia, 1995), na que se conta unha lúdica transgresión de identidades, con trazos do realismo máxico e con diálogos moi logrados, mediante os que manifesta a condición posmoderna dos personaxes; Os fillos do río (Vigo, Galaxia, 1999), novela póstuma que reproduce un cadro do Ourense dos anos cincuenta e onde sobrancea indirectamente unha homenaxe a Vicente Risco. Esta novela comparte con Margarida D'ouriac (Sada, O Castro 1992) unha asistemática mestura lingüística entre galego e portugués; por último, na tamén póstuma Tánata (Vigo, Xerais, 1998) reflexiónase arredor da morte desde os postulados do existencialismo.

A década dos noventa supuxo a consolidación de MANuEl Rivas (A Coruña, 1957) como narrador e como un dos fenómenos máis relevantes do sistema literario galego destes anos. Así pois, teriamos que considerar o alto nivel de vendas das súas obras (algo inaudito ata esta altura), a case simultánea publicación dos seus libros en castelán e a súa venda en Galicia, a realización dunha película baseada nun dos seus contos («A lingua das bolboretas») e outras moitas cuestións relativas ao seu recoñecido traballo como xornalista, e polo tanto de fama nos medios de comunicación. Todo isto habería que o tratar noutro lugar con maior espacio e demora. A súa obra narrativa divídese en libros de relatos: ¿Que me queres amor?26 (Vigo, Galaxia, 1995; Premio Nacional de Narrativa 1996) nos que conviven o máxico e o real, e onde se relaciona o imaxinario cultural dos arrabaldes das cidades co mundo esgazado e difícil de encaixar debido aos novos e rápidos hábitos que deben asumir os seus habitantes. En Ela maldita alma (Vigo, Galaxia, 1999) interrógase, mais que se responde, sobre a ontoloxía da alma, a través de contos baseados, na maioría dos casos, en anécdotas. No derradeiro Nadal do milenio publicou dous relatos curtos, entre os que se entremete un feixe de fotografías, titulado A man dos paíños (Vigo, Xerais, 2000). Desta obra, da súa breve extensión, da súa valía literaria, da súa intencionalidade editorial, e doutras cuestións, algún crítico ten dito, entre outras cousas: «A literatura galega non está como para andar xogando cos lectores, e moito menos que o faga un dos seus autores máis coñecidos, con máis carisma, e que goza das simpatías do público» 27 . O seu corpos narrativo de ficción deste anos complétase coas novelas: Os comedores de patacas (Vigo, Xerais 1991), obra iniciática de personaxe infantil; En salvaxe compaña (Vigo, Xerais 1993), intento de recrear a memoria histórica galega determinada por un explícito simbolismo, e $O$ lapis do carpinteiro (Vigo, Xerais 1997), novela de grande suceso entre o público e os lectores, que conta, cun estilo directo e cunha lingua neutra e fluída, de grande lirismo, unha historia acontecida nos tempos da guerra na que abrolla a tenrura dos personaxes, que só posúen ideas, fronte á barbarie fascista. Con esta obra pro-

26 Dez destes relatos recibiron o Premio Torrente Ballester 1995.

27 Xosé Manuel EIRÉ, «Un escritor na encrucillada», A Nosa Terra, n. ${ }^{9} 968,4$ de xaneiro 2001, p. 24. 
cura a redención das moitas víctimas e fai unha homenaxe á dignidade, representada no protagonista 28 .

En situación similar encóntrase SUSO DE TORO, que representa tamén unha das voces con máis repercusión, tanto creativa como mediática, desta década. Froito da maduración como creador, despois daquel rompedor Polaroid (Vigo, Xerais, 1986), veu a luz Tic-tac (Barcelona, Ediciones B, 1993). Mediante unha técnica fragmentaria, con recursos típicos do cine, o autor crea un mundo fronteirizo campo-cidade protagonizado por Nano, un personaxe marxinado e lúcido que lle confire unidade a unha obra poderosísima e dunha riqueza de matices e formas que constitúe, ao noso parecer, a súa cima narrativa ata este momento. Esta feliz realización quere ter unha continuación en Círculo (Vigo, Xerais, 1998), que retoma o mundo narrativo-ficcional da anterior obra e que, malia ao conseguido intento totalizador, acaba de enxalzala aínda máis. Por outra parte, Calzados Lola (Vigo, Xerais 1997) representa o comezo, xa iniciado de xeito irregular con Ambulancia (Vigo, Xerais, 1990), do cultivo de novelas de estructura tradicional, máis afastadas tanto narrativa como conceptualmente do fragmentarismo das máis características deste autor, sinaladas máis arriba. Nela cóntase unha trama localizada en Madrid pero que leva os protagonistas a volver a Muros, á busca da súa propia identidade. Na mesma liña está Non volvas (Vigo, Xerais, 2000), que narra a volta ao pasado dunha muller tras unha crise, para enxuizar e romper cunha serie de enigmas sufridos polos seus, que ficaran sen resolución, e que, ao tempo, determinaban o seu existir. Non poderiamos deixar de falar da novela de ciencia-ficción A sombra cazadora (Vigo, Xerais, 1994), que, malia estar na colección Xuvenil «Fóra de xogo» da editorial Xerais, non é nada inxenua nin infantil pois presenta a dous rapaces fuxindo da televisión que os acosa a xeito, a xeito de hipérbole da realidade mediática que nos asoballa hoxe en día ${ }^{29}$.

\subsection{ESCRITORES QUE COMEZARON A PUBLICAR NESTA DÉCADA DOS NOVENTA}

\subsubsection{Escritores que xa son un referente na actualidade}

O poeta e narrador Fran Alonso (Vigo, 1963) comezou a década con éxito logo de a súa obra Tráiler (Vigo, Xerais, 1991) resultar gañadora do Premio

28 Aínda que non é aquí o lugar adecuado quixeramos, por outra parte, lembrar os libros nos que se recolle a crónica xornalística-Toxos eflores (Vigo, Xerais, 1992), Galicia, Galicia (Vigo, Xerais, 1999)- que revelan un Manuel Rivas movéndose coma peixe na auga, mesmo salpicándonos.

29 Neste punto cómpre citar o ensaio Parado na tormenta (Vigo, Galaxia, 1996) por supor unha declaración de principios ideolóxicos, creativos e humanos de grandísimo interese que ispe o autor diante de «nós", curiosos lectores, que descubrimos a árbore entre tanto bosque. Algo que deberían imitar outros moitos, non por necesario, senón pola complicidade e claridade na relación autor-lector /a (es/as). 
Blanco Amor dese ano. Trátase dunha novela de boa feitura e boa acollida polos lectores, o que fixo que a editorial a reeditara en formato de peto en 1998. Nela cóntase, cun prosa realista, unha viaxe habitual dun camioneiro, na que tamén se reflicten os seus problemas ao volante, na casa, coa familia, etc. Consegue un grande equilibrio entre o mundo tradicional e o mundo moderno no que se moven estes traballadores e presenta, ao igual que nos relatos de Cemiterio de elefantes (Vigo, Xerais, 1994), un ritmo narrativo áxil que tira polo lector, acompañado, nesta última obra, por un efectivo ton sarcástico.

Con moita forza creadora e valía narrativa xorde no panorama literario galego XURXo BorRaZÁs (Carballo, 1963) cunha primeiriza obra, Cabeza de Chorlito (Santiago de Compostela, Sotelo Blanco, 1992), que vén ser un exercicio lúdico e un experimento metaliterario. Despois publicaría a novela Criminal (Santiago de Compostela, Sotelo Blanco,1994), de poderosa composición e ficción. Con códigos clásicos da novela negra artéllase esta obra fragmentaria, esgazada narrativa e humanamente, adiviñada coas retrospeccións e descuberta coas prospeccións. Á beira da propia diéxese desenvólvese o conflicto sobre o que representa a creación literaria e a súa recepción. Este mesmo problema agroma dun xeito explícito en Eu é (Santiago de Compostela, Sotelo Blanco, 1996), esoutro xogo complexo de realide-ficción no que o lector se ve envolto e avolto e que a crítica ten considerado cos postulados dunha novela posmoderna ${ }^{30}$. Esta andaina novelesca rematou, polo momento, esperemos, con $\mathrm{Na}$ maleta (Santiago de Compostela, Sotelo Blanco, 2000) que, situada nos mesmos principios literarios cás anteriores, manifesta a desolación pola ausencia de destino. En canto ao relato curto, despois dos Contos malvados (Vigo, Xerais, 1998), publicou un conxunto heteroxéneo de pezas breves de carácter ficcional e/ou ensaístico titulado $O$ desintegrista (Vigo, Xerais, 1999), no que, como dixemos ao falarmos de Suso de Toro, fican claras moitas das teimas, posicións e criterios do escritor.

Outro prolífico e recoñecido narrador destes anos foi Alfonso Álvarez CÁCCAMo (Vigo, 1952), que publica inicialmente As baleas de Eduardo Reinoso (Vigo, Xerais, 1990; Premio Xerais, 1990), novela irregular caracterizada polo xogo humorístico e a complexidade das imaxes. Posteriormente dá ao prelo Xente de mala morte (Vigo, Xerais 1993; Premio Álvaro Cunqueiro 1993), un libro de relatos definidos polo suicidio. Coa novela $O$ espírito de Broustenac (Vigo, Xerais, 1996; ex aequo Premio de Novela Manuel García Barros 1996), compón unha peza histórica, mais de compoñente fantástica, caracterizada pola fluidez da súa prosa e pola ironía e o humor coma tamén ocorre nos Contos mamíferos (Vigo, Do Cumio, 1998). Son estas características definitorias do autor.

30 Cfr. Dolores VilavedRa, «Unha novela posmoderna. Xurxo Borrazás: Eu é», Sobre narrativa galega contemporánea, Vigo, Editorial Galaxia, 2000, pp. 153-155; «Introducción» a Inmaculada Otero Criminal. Eu é. Dúas novelas de Xurxo Borrazás, Santiago, Sotelo Blanco, 2000 , p. 3. 
Outro autor de carreira meteórica que naceu literariamente coa década e que acadou o máximo apoxeo e recoñecemento no seu final, despois de nos deixar un feixe de novelas de grande impronta por unhas ou outras razóns, que acadaron o éxito en premios pero que non conseguiron, aínda, gañar o exiguo lectorado galego (de narrativa galega, queremos dicir), é XOSÉ CARLOS CANEIRO (Verín, 1963). Comezou en 1992 coa novela $O$ infortunio da soidade (Vigo, Xerais, 1992; Premio Xerais de Novela 1992), na que presentaba un mundo propio caracterizado pola intensidade expresiva, pola densidade e pola complexidade de formas e personaxes que caracterizarán toda a súa obra posterior, concibida polo propio autor coma unha pentaloxía. O seguinte chanzo será, ao noso parecer, unha das novelas máis ricas destes anos: Un xogo de apócrifos (Vigo, Xerais, 1997; Premio Torrente Ballester 1996) que, cunha milimetrada estructura e unha prosa moi coidada, traza un xogo intertextual no que se plasman os temas universais da literatura, entre os que sobresae o fracaso e o absurdo vital, como fachos que atravesarán todas as súas obras. Posteriormente dá a luz no mesmo ano dúas novelas: Os séculos da lúa (A Coruña, Espiral Maior, 1999), obra de grande extensión e capacidade creativa onde, cun poético e melancólico ton, hai un complexo mundo de intertextualidades; e Tal vez melancolía (A Coruña, Espiral Maior, 1999; XI Premio García Barrros), que, artellada a modo de diario, descríbenos a desolada vida dun profesor durante oitos anos, con desenvolvemento linguístico preciso e con enredos (acrósticos...) literarios que lle fan choscadelas ao lector. A última entrega deste macrotexto é a triunfante, caso excepcional na literatura galega o de conseguir dous premios no mesmo día, Ébora (Vigo: Xerais, 2000; Premio Eixo Atlántico de Narrativa Galego-Portuguesa 2000 e Premio Blanco Amor 2000). Esta extensa novela vén pechar un ciclo narrativo dunha maneira contundente, continuando a complexidade constructiva das anteriores obras mais cunha dose de aventura maior o que permite unha mellor facilidade na lectura. Entre tanto publicou tamén a novela $A$ rosa de Borges (Santiago de Compostela, Sotelo Blanco, 2000; Premio de Narrativa Fantástica Vicente Risco), onde atopamos como novidade unha protagonista feminina e uns relatos intercalados de carácter fantástico.

XosÉ Cid CABIDo (Xunqueira de Ambía, 1959) comezou a década, despois de se estrear no eido do teatro e da narrativa anteriormente, co libro de relatos Días contados (Vigo, Xerais, 1991; Premio Cidade de Lugo 1991), nos que predomina unha técnica cinematográfica, apoiada nunha sintaxe directa á que volve en Panificadora (Vigo, Xerais, 1994; Premio Blanco Amor 1994), onde se tematiza o absurdo do sistema capitalista. Posteriormente os relatos de $\mathrm{Oral}$ mente pola boca (Vigo, Xerais, 1997), continúan nesa literatura do absurdo que será premiada na novela Grupo Abeliano (Vigo, Xerais, 1999; Premio Blanco Amor 1999) e que, como as anteriores, supón un banzo máis nesa súa proposta narrativa, por el mesmo cualificada de evidencialista.

Un autor que deixou nestes anos proba do seu bo labor literario é BiErTo IGLESIAS (Quintián, Ourense, 1957), quen se estreou con Aventura de Nassau (Vigo, Xerais 1991), un libro de relatos de temática erótica no que se combina 
un humor negro, a aceda ironía, e unha grande riqueza lingüística que, xunto aos finais climáticos, configuran unha escrita moi persoal. Estas mesmas características narrativas, aínda que cunha temática policial aparecen nos relatos de Miss Ourense (Vigo, Galaxia, 1994), ou nos máis recentes de $O$ mellor francés de Barcelona (Vigo, Galaxia, 1999), obra que trata os temas do sexo, a violencia, a loita polo poder ou a morte. Como novelista deu ao prelo a obra Vento de seda (Vigo, Xerais, 1993) na que (re)crea memorias xeracionais, polo que a crítica a considerou unha novela de autocoñecemento ${ }^{31}$. Resta dicirmos, polo demais, que este autor presentouse e gañou en 1999 un premio cunha obra escrita en castelán, (Premio Ciudad de Salamanca coa novela Bajo las más bellas estrellas) co que parece que buscou explicitar o que outros fan implicitamente, isto é , procurar o éxito no sistema literario español e a súa repercusión no sistema literario galego. Mais, o tempo dirá se estas aventuras dan o resultado agardado ou se fican nun experimento narcisista propio dos escritores.

A escritora Marina Mayoral (Mondoñedo, 1942) publicou o libro de relatos Querida amiga (Vigo, Galaxia, 1995), narrados cunha técnica epistolar e nos que recrean cinco historias do mundo dos sentimentos, cunha linguaxe moi apegada á oralidade. Esta foi a única obra en galego que publicou nestes anos, pero en castelán deu ao prelo varias.

Xosé MiRanda (Lugo, 1955) é un autor de prolífica obra nestes anos. Así, deu a luz, entre outras: Historia dun paraugas azul (Vigo, Xerais, 1991), que presenta unha prosa ornamental de grande calidade, debedora da tradición literaria galega; $O$ demo á orella (Vigo, Xerais, 1996) feixe de relatos curtos que configuran un mundo desesperanzado, cunhas tramas que van desde a Prehistoria ata a Idade Moderna; A biblioteca da Iguana (Vigo, Xerais, 1994), conxunto de oito relatos de grande mestría narrativa que teñen na densidade e no lirismo dous dos elementos máis salientábeis; e por último, a exitosa Morning star (Vigo, Xerais, 1998; Premio Xerais 1998), unha novela de aventuras que engancha ao lector pola grande axilidade narrativa e por tratar un tema sempre suxerinte como é o dos piratas e bandoleiros, enmarcado nun cambiante século XIX, neste caso en explícita homenaxe ao pirata galego Benito Soto.

Un autor de moita obra premiada nesta década, pois practicamente gañou todos os premios de relatos, e algúns de novelas, que hai no sistema literario galego, algúns incluso repetindo galardón nalgunha ocasión, é o ourensán ANTón Riveiro CoEllo (Xinzo de Limia, 1964). De entre as varias obras que publicou só comentaremos as seguintes: A Quinta de Saler (Vigo, Galaxia, 1999; Finalista do Premio Torrente Ballester 1999), xogo intertextual e metaliterario, sen saír do sistema literario galego ${ }^{32}$, de aí a súa relevancia, onde, cun

31 Vid. Ana María SPITzmesser, «Ritos de pasaxe: a búsqueda de identidade en Vento de seda, de Bieito Iglesias», Grial, n. ${ }^{9} 129$, xaneiro-febreiro-marzo, Tomo XXXIV, 1996, pp. 16-23.

32 Vid. Anxo Tarrío VArela, «Ideoloxía e novela» en Dorna, n.․ 9, 1985; X. GonzálezMillán, Literatura e sociedade en Galicia (1975-1990), Vigo, Xerais, 1994. Estes críticos puxeron de manifesto a necesidade dunha intertextualidade interna para a literatura galega.. 
ritmo áxil, se conta cómo se constrúe unha novela. Para iso toma elementos aventurescos e fantásticos con certas doses de intriga, que a converten nunha novela de fácil lectura. Tamén publicou, entre outros, un interesante libro de relatos Animalia (Vigo: Galaxia, 2000) ${ }^{33}$ onde se presentan situacións fantásticas definidas por un final de grande tensión climática. Por último, no final do ano 2000 gañou o Premio de Novela Manuel García Barros coa obra As rulas de Bakunin (Vigo, Galaxia, 2000). Nesta obra de lectura agradábel preséntase unha viaxe a través do século pasado da man do anarquista que a protagoniza.

\subsubsection{Escritores que deron os primeiros pasos na década}

ANXo ANGueIRa (Manselle, Dodro, 1961) tivo unha posta en escena que nos permite agardar grandes obras. A primeira publicación foi Bágoas de facer illas (Vigo, Xerais, 1997; Premio Café Dublín, 1996). Trátase dun libro de grande capacidade sintética, alto nivel expresivo, densidade verbal e lirismo, que presenta unha fermosa factura. Por outra parte, a novela Pensa nao (Vigo, Xerais, 1999) obtivo o Premio Xerais 1999. É unha crónica de ficción dos momentos previos á Guerra Civil, na que se mestura o mundo agrario, o progresismo, o galeguismo, as referencias á emigración e unha historia de amor que adobía un fondo doloroso pola morte que trouxeron os alzados. Todo isto está narrado con grande riqueza lingüística.

Ramón Caride Ogando (Cea, 1957) escribiu un feixe desigual de obras. Comezou con Soños eléctricos (Vigo, Xerais, 1992), gañadora do Premio Blanco Amor 1992, na que se achega ao xénero de ciencia ficción. Outra súa obra foi Sarou (Vigo, Xerais, 1997; Premio Café Dublín, 1997), onde se presenta unha novela negra rápido ritmo narrativo e especialización léxica na que se simboliza un caso de drama colectivo. Ademais, con Fendas no tempo (A Coruña, Espiral Maior, 1995) preséntanos uns relatos sintéticos e orixinais que mostran a súa capacidade narradora.

Manuel Darriba (Sarria, 1973), logo da inicial, e exitosa, Paf Xarope (Santiago de Compostela, Sotelo Blanco, 1997), tira do prelo Outonos espectaculares (Santiago de Compostela, Sotelo Blanco, 1998), na que, determinada por accións nas que reflicte a vida cotiá, presenta uns traballados diálogos de grande naturalidade e orixinalidade.

O xornalista ANíBal MaLVAR (A Coruña, 1964) publicou catro novelas que presentan características compositivas comúns. Un home que xaceu aquí (Vigo, Xerais, 1993) e A man dereita (Santiago de Compostela, Sotelo Blanco, 1994; Premio Manuel García Barros 1994) presentan un relato policial, no que se mostra un emprego habilidoso dos diálogos para facer parábolas das realidades cul-

33 Algúns dos contos recollidos neste volume resultaron gañadores do Premio Café Dublín 1999 e outros do Modesto R. Figueiredo. 
tural e política do país, respectivamente. Unha noite con Carla (Vigo, Xerais, 1995; Premio Xerais de Novela 1995) é unha novela negra caracterizada pola axilidade dos diálogos que ensarillan unha trama detectivesca baseada no xornalismo de investigación. E, por último, Á de mosca (Vigo, Xerais, 1998) abonda no xénero negro coas boas maneiras que demostrara anteriormente.

Xavier ManTeiga (Santiago de Compostela, 1968) deu ao prelo Morrer na herba (Santiago de Compostela, Edicións Positivas, 1995), novela de características cinematográficas na que predominan os diálogos. Trátase dunha novela ambientada no medio rural, que presenta dinámico desenvolvemento narrativo. Seguindo estas características publicaría Sinfonía inacabada (Santiago de Compostela, Edicións Positivas), na que consegue un final sorprendente. Así mesmo, en Manancial (Vigo, Xerais, 1997; Premio Xerais 1997) narra, ao xeito dunha traxicomedia, unha historia onde ten unha forte pegada a violencia e o absurdo.

Manuel NúÑEz Singala (Lugo, 1963) publicou Mar de fondo (Vigo, Galaxia, 1997), un libro que pasou case desapercibido, quizais por sair nun formato de peto ${ }^{34}$, mais que presenta unha axilidade narrativa e un dominio dos recursos estilísticos que, xunto á riqueza linguiística e á ironía, fana unha obra moi interesante, polo que haberá que estar atento ás futuras entregas deste autor.

XAVIER QUEIPo (Santiago de Compostela, 1957) estreouse coa publicación de Ártico (Vigo, Xerais, 1990), libro caracterizado pola ironía que presenta grande complexidade linguística e constructiva. Outras obras foron: Contornos. Apuntes de filosofía natural (Vigo, Xerais, 1995), conxunto de composicións narrativas breves, entre o relato e o ensaio, nas que se mestura literatura e bioloxía; Os exóticos relatos de Ringside (Santiago de Compostela, Sotelo Blanco, 1994) sitúan o lector en espacios afastados e noutras épocas con argumentos da novela de aventuras; e $O$ paso do noroeste (Santiago de Compostela, Sotelo Blanco, 1996; ex aequo ao VII Premio Manuel García Barros 1996), obra de aventuras definida por ser unha novela marítima.

MANUEl SEIXAS (Vilagarcía, 1961) conseguiu triunfar en 1996 con A velocidade do frio (Vigo, Xerais; Premio Xerais 1996), novela de intriga na que se barralla cos problemas do home contemporáneo, que é representado como un ser solitario, metido nun coche, espacio simbólico da súa deshumanización. Para iso emprega estratexias narrativas baseadas en monólogo e diálogo, cun rápido ritmo; en Bailarina (Vigo, Xerais, 1999) presenta unha novela de ciencia-ficción situada nun futuro afastado que, malia o intento, deixa un pouso moralizante.

34 A este respecto cómpre dicir que a publicación de obras neste formato relégaas a un segundo nivel, porque este é un formato secundario, empregado para reedicións comentadas de clásicos, e para popularizar certas obras que xa estaban «esquecidas» polo mercado. Con isto queremos dicir que unha novidade literaria nun formato de peto ten moitas posibilidades de ficar nun segundo plano. 


\subsubsection{Libros de relatos}

A tradición contística galega presenta unha riqueza admirábel, debido, fundamentalmente a sermos unha sociedade rural, co que o predominante era o relato de tradición oral, e máis tarde escrito. Coa Xeración Nós daríanse os primeiros intentos serios de crear un texto literario xa que os contos adquiriron unha nova perspectiva que se foi asentando ata os nosos días nos que gozamos de autores que cultivan o relato literario, non exclusivamente tradicional, con grande mestría.

Baixo este epígrafe queremos agrupar, sen ningún afán clasificatorio, os libros de relatos (e os seus autores) que, ao noso parecer, foron, alén dos xa sinalados ao falarmos de outros escritores de novelas, os máis relevantes para o mundo editorial, para a evolución do xénero, para os lectores e para a crítica nestes anos noventa.

A escritora Marica CAMPo (Val do Incio, 1948) publica a Confusión e morte de maría Balteira (A Coruña, Bahía, 1996). Trátase dun conxunto de relatos contados cun lirismo expresivo e con grande sensibilidade e protagonizados por misteriosas mulleres.

Uxía CaSAL (Santiago de Compostela, 1957) publicou Saturno tamén é deus (Vigo: Galaxia, 1997). Neste conxunto de contos de medo, fantásticos e de morte hai grandes doses de intriga e suspense ata o último momento, polo que consegue finais de grande intensidade.

Belén Feliu (A Coruña, 1961- Santiago de Compostela, 1997) publicou un único libro: $D a$ Guenizah (A Coruña, Espiral Maior, 1998), que veu luz pouco despois do seu pasamento. Trátase dun simbólico conxunto de narracións a modo de epopea para se enfrontar á traxedia. Presentan unha linguaxe densa, lírica e irónica con rexistros variados cos que expresa motivos coma a violencia ou a represión.

O xornalista e crítico teatral CAmILo Franco (Ourense, 1963) tirou do prelo En malos pasos (Vigo, Xerais, 1995). Achéganos nove relatos baseados en feitos da vida cotiá con trazos de ironía e xogos verbais, alén dunha linguaxe directa, que veñen configurar un discurso narrativo moi variado, malia o seu pouso pesimista. Deste escritor debemos comentar tamén o seu carácter pioneiro no emprego dos novos soportes para a creación literaria, xa que foi o autor dun libro de relatos escrito a partir de dúas palabras que os internautas lle enviaban ao buscador galego Vieiros. É pois na rede onde se pode ler o resultado desta experiencia «interactiva» que levou por título Por conto alleo (2000).

O xornalista Santiago JaUREgUIZAR (Bilbao, 1965) publicou Freedom speak (Vigo, Xerais, 1995), irreverente conxunto de pezas narrativas, de impronta reveladora e construcción sintética nas que se ofrece unha visión da sociedade rural galega en proceso de adaptación aos trocos da modernidade. Fronte a esta anovadora proposta publicou despois a pouco interesante Comendo espaguetis diante da televisión (Vigo: Xerais, 1998). 
O tamén guionista Miguel ANXo Murado (Lugo, 1965) publicou un conxunto de relatos sobre a guerra de Bosnia, Ruído. Relatos de Guerra (Vigo, Galaxia, 1995) e anos máis tarde, Mércores de cinza (Vigo, Galaxia, 1998) conxunto de relatos marcados pola brevidade nos que aboia a dor humana. Da narración trasloce a dor e o pesimismo, mais fan revivir ao lector con cada ilusión nese camiño cara á nada, de aí o pouso de optimismo que permanece.

O polifacético profesor GonZalo Navaza (Lalín, 1957) puxo nas librerías Erros e tánatos (Vigo, Xerais, 1996; Premio da Crítica Española e Premio San Clemente 1999). Son dez relatos que tiveron moi boa acollida de crítica e público. Neles hai misterio, fantasía, realidade, maxia, intriga, ludismo, etc., e tamén paixón, dor, emoción e ironía, narradas con suma precisión, con clímax precisos, cunha linguaxe puntual que o converte nun dos libros de relatos máis sobresaíntes da década, e que nos deixa desexosos de futuras entregas deste autor.

PAULINo PEREIRo (A Coruña, 1957) ofrécenos unha peculiar narración en Dende unha mesa de café (Santiago de Compostela, Laiovento, 1998). Trátase dun feixe de vintetrés relatos de feitura desigual, construídos ao xeito dun quebracabezas nos que predomina o amor e a soidade.

O artista, escritor e músico XURXo SouTo (A Coruña, 1966) publicou A tralla e a arroutada (Vigo: Xerais, 1995) e dous anos despois Fumareu (Vigo, Xerais, 1997), nos que atopamos crónicas de viaxes co seu grupo de música, propostas mitificadoras, experiencias singulares con doses de humor e dinámico ritmo que teñen como fin último a defensa da identidade, e supoñen a expresión dos principios da estética Bravú, do que Xurxo Souto é o principal ideador e defensor ${ }^{35}$.

Xelís dE Toro (Santiago de Compostela, 1962) publicou entre outros Non hai misericordia (Santiago de Compostela, Edicións Positivas, 1990; Premio Cidade de Lugo 1990). Este conxunto orixinal de relatos teñen como protagonista a violencia, á que se ven arrastrados uns personaxes urbanos que podería ser unha persoa calquera levada polo arrasador modo de vida contemporáneo.

\section{8. $\mathrm{CABO}$}

Nesta viaxe pola narrativa galega máis recente non queremos deixar de sinalar, por unha parte, a grande calidade de moitas das obras publicadas, e, por outra, a necesidade case imperiosa de conseguir que as letras galegas poidan chegar aos andeis das librerías e ás casas dos lectores con maior asiduidade. Falla fundamentalmente a transmisión: é moi importante producir obras boas

35 Neste punto, quixeramos citar a súa novela marítima $O$ regreso dos homes mariños (Vigo, Xerais, 1999) por tratarse dunha representante desta temática moi escasa nun país con tantos quilómetros de costa. 
pero tamén que a sociedade as acolla. Para iso, como xa adiantamos máis arriba, requírese maior apoio das institucións, e non só como mecenas ${ }^{36}$, que tamén, senón como promotoras de industrias culturais que poidan incidir positivamente na «normalización» da literatura galega, o que, sen dúbida, iría parello á normalización da lingua, chanzo básico para conseguir o primeiro. Tamén se debe mellorar, a situación da crítica, creando novos espacios e máis liberdade para que non ocorra como está a suceder neste momento no que moitos críticos só fan recensión de obras que lles gusten sen entrar a cuestionar outras. Polo demais cómpre unha maior especialización das editoriais, xa se sabe que non se pode entender a todo, ou polo menos non coa mesma calidade.

En definitiva, no panorama socio-político-cultural dos anos noventa a narrativa galega foi o xénero de maior impronta social e quizais de representatividade simbólica da literatura galega, que dominara tradicionalmente o xénero poético. Tendo en conta o visto ata aquí podemos concluír que a narrativa galega goza de bastante vitalidade xa que presenta algunhas características de especial relevancia para vivir nunha situación complexa. Por este motivo, a súa pervivencia parece asegurada, máxime se temos en conta que apareceron novos escritores, que se produciu unha ampliación e rexeneración das temáticas e que se evoluiu canto ao emprego das novas técnicas narrativas o que lle permitiu acadar cumios narrativos equiparábeis ao de calquera narrativa do seu contorno, o que, a priori, é garantía de venturosos agoiros. Isto non debe impedirnos observar certa debilidade que, ao noso xuízo, demostran algunhas facetas do sistema literario galego, xa sinaladas, aspectos que se deberán mellorar non vindeiros anos.

\section{REFERENCIAS BIBLIOGRÁFICAS}

Figueroa, Antón, Diglosia e texto, Vigo, Xerais, 1988.

GONZALEZ-MILlÁN, X., A narrativa galega actual (1975-1984), Vigo, Xerais, 1996. Aproximación á narrativa galega, Grial, n..$^{9} 127$, xullo-agosto-setembro, 1995.

RoIG ReCHOU, Blanca Ana (coord.) Informe de literatura galega 1995, 1996, 1997, 1998 e 1999, Santiago de Compostela, Centro Ramón Piñeiro de Investigación en Humanidades, 1996, 1997, 1998, 1999, 2000.

TARRIo Varela, Anxo, Literatura galega. Aportacións a unha historia crítica, Vigo, Xerais, 1994, 2.' ed. 1998.

VIlAVEDRA, Dolores, Historia da literatura galega, Vigo, Galaxia, 1999.

VILAVEDRA, Dolores, Sobre narrativa galega contemporánea, Vigo, Galaxia, 2000.

VILAVEDRA, Dolores (Coord.), Diccionario da literatura galega, III Obras, Vigo, Xerais, 2000.

36 Sería moi interesante comprobar os usos que moitas institucións (sobre todo concellos) fan dos orzamentos asignados á cultura. Pois, moitas veces dedicános á convocatoria dun premio literario deixando absolutamente ermo todo o ano o resto do campo cultural. Por non falarmos da falla de promoción da lectura, nin sequera dos libros que eles mesmos premian. 